\title{
Data constraints on ocean-carbon cycle feedbacks at the mid-Pleistocene transition
}

\author{
Jesse R. Farmer ${ }^{1,2}$, S.L. Goldstein ${ }^{3,4}$, L.L. Haynes ${ }^{3,4}$, B. Hönisch ${ }^{3,4}$, J. Kim³ ${ }^{3,4}$ L. Pena ${ }^{5}$, M. Jaume-Seguí ${ }^{5}$ and \\ M. Yehudai ${ }^{3,4}$
}

\section{The mid-Pleistocene transition marks the final turn of the Earth system towards repeated major ice ages after $\sim 900,000$ years ago. Recent advances in paleoceanographic research provide insight into how ocean processes facilitated the climate changes at that time.}

\begin{abstract}
Approximately 900,000 years ago $(900$ kyr BP), ice ages switched from occurring every 41 kyr to every 100 kyr, lengthening in duration, and strengthening in terms of cooling and ice volume. This "midPleistocene transition" (MPT) occurred without notable changes in Earth's orbit around the sun (i.e. incoming solar radiation). Lacking a defined external trigger, the MPT must represent a fundamental reorganization of Earth's internal climate system, including its greenhouse gas composition, ocean circulation, seawater chemistry, and/or development of more favorable conditions for ice-sheet growth. Recent advances in paleoceanography have made significant progress towards identifying when, how, and why the different components of Earth's climate system changed across the MPT. Here we summarize the biogeochemical insights gleaned from ocean sediments that directly reflect on the global carbon cycle (Fig. 1).
\end{abstract}

The global climate state of the mid-Pleistocene can be inferred from the benthic foraminiferal oxygen isotope stack of Lisiecki and Raymo (2005) (Fig. 2a), which integrates deep-ocean temperatures and global ice volume. This record shows the MPT as the transition from 41-kyr glacial cycles prior to $1250 \mathrm{kyr}$ BP to dominant 100-kyr glacial cycles by 700 kyr BP (Fig. 2, light blue shading). Within this interval, an anomalously weak interglacial stands out at $900 \mathrm{kyr}$ BP (the "900 ka event"), at the midpoint of what is considered the first 100-kyr glacial cycle (Fig. 2, dark blue shading; Clark et al. 2006).

Proposed explanations for the MPT often in voke declining atmospheric carbon dioxide $\left(\mathrm{CO}_{2}\right)$ as a fundamental tool to change the climate response to orbital forcing (Clark et al. 2006). Available $\mathrm{CO}_{2}$ reconstructions during this time period are of low temporal resolution but suggest that glacial $\mathrm{CO}_{2}$ decreased by 20-40 ppm sometime between ca. 1000 and ca. 800 kyr BP (Fig. 2b). The ocean most likely caused this $\mathrm{CO}_{2}$ decline via enhanced biological $\mathrm{CO}_{2}$ uptake and/or reduced release of sequestered $\mathrm{CO}_{2}$ back to the atmosphere. General Pleistocene model simulations (Chalk et al. 2017; Hain et al. 2010) highlight three pathways for glacial ocean $\mathrm{CO}_{2}$ sequestration: weaker deep-ocean circulation, increased ocean biological productivity through iron fertilization, and reduced $\mathrm{CO}_{2}$ exchange between deep waters and the ocean surface (broadly termed "stratification"). The common premise behind these pathways is that the missing atmospheric $\mathrm{CO}_{2}$ was trapped in the deep ocean.

\section{Records of ocean circulation}

Earlier attempts to reconstruct deep-ocean circulation across the MPT relied on benthic foraminiferal carbon isotope ratios $\left(\delta^{13} \mathrm{C}\right)$. However, regional biology, air-sea gas exchange, and the size of the terrestrial biosphere also impact deep-ocean $\delta^{13} \mathrm{C}$ hindering quantitative circulation reconstructions (Lynch-Stieglitz and Marchitto 2014). In contrast, neodymium isotopes $\left(\varepsilon_{\mathrm{Nd}}\right)$ provide a potentially quantitative approach to separate deep-ocean waters of different geographical origins (Blaser et al. this issue). Distinct $\varepsilon_{\mathrm{Nd}}$ values for North Atlantic-sourced and Pacific-sourced deep waters are set by weathering of older and younger continental material into each basin, respectively. In the modern ocean, $\mathrm{Nd}$ isotopes behave "quasi-conservatively"; that is, they reflect water-mass mixing, and are not substantially fractionated by biological or physical processes. Moreover, North Atlantic and Pacific end-member $\varepsilon_{\mathrm{Nd}}$ values have remained approximately constant over the Pleistocene (Pena and Goldstein 2014).

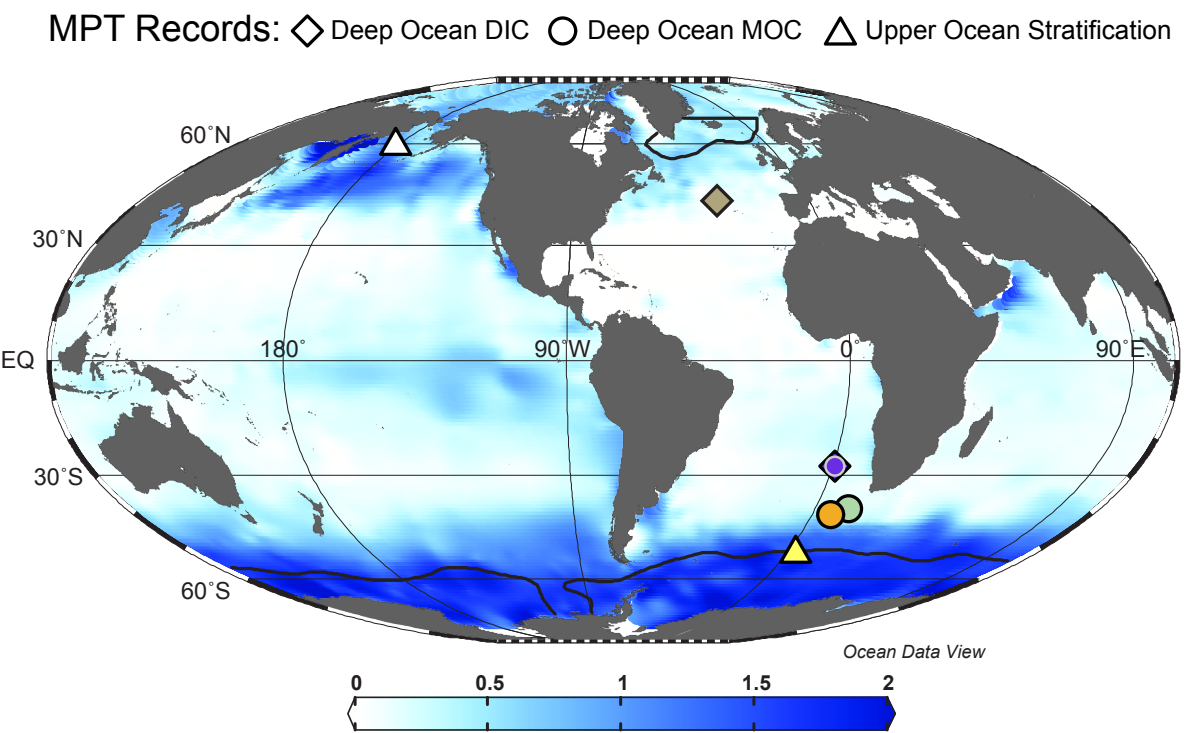

Surface Ocean Phosphate $(\mu \mathrm{mol} / \mathrm{kg})$

Figure 1: World map of surface-ocean phosphate concentrations (from GLODAP v2; Lauvset et al. 2016) and core sites of MPT ocean circulation and carbon-cycle reconstructions. A limiting nutrient for ocean productivity, phosphate occurs at high concentrations in areas of the surface ocean where biological consumption of carbon is inefficient, thus limiting ocean uptake of atmospheric $\mathrm{CO}_{2}$. Regions with sufficiently dense surface water to form deep waters (black contour) directly link surface ocean nutrient consumption with deep-ocean circulation and carbon storage. Broadly, enhanced nutrient consumption in these regions lowers atmospheric $\mathrm{CO}_{2}$. Symbols and colors of core locations match data series shown in Figure 2. 


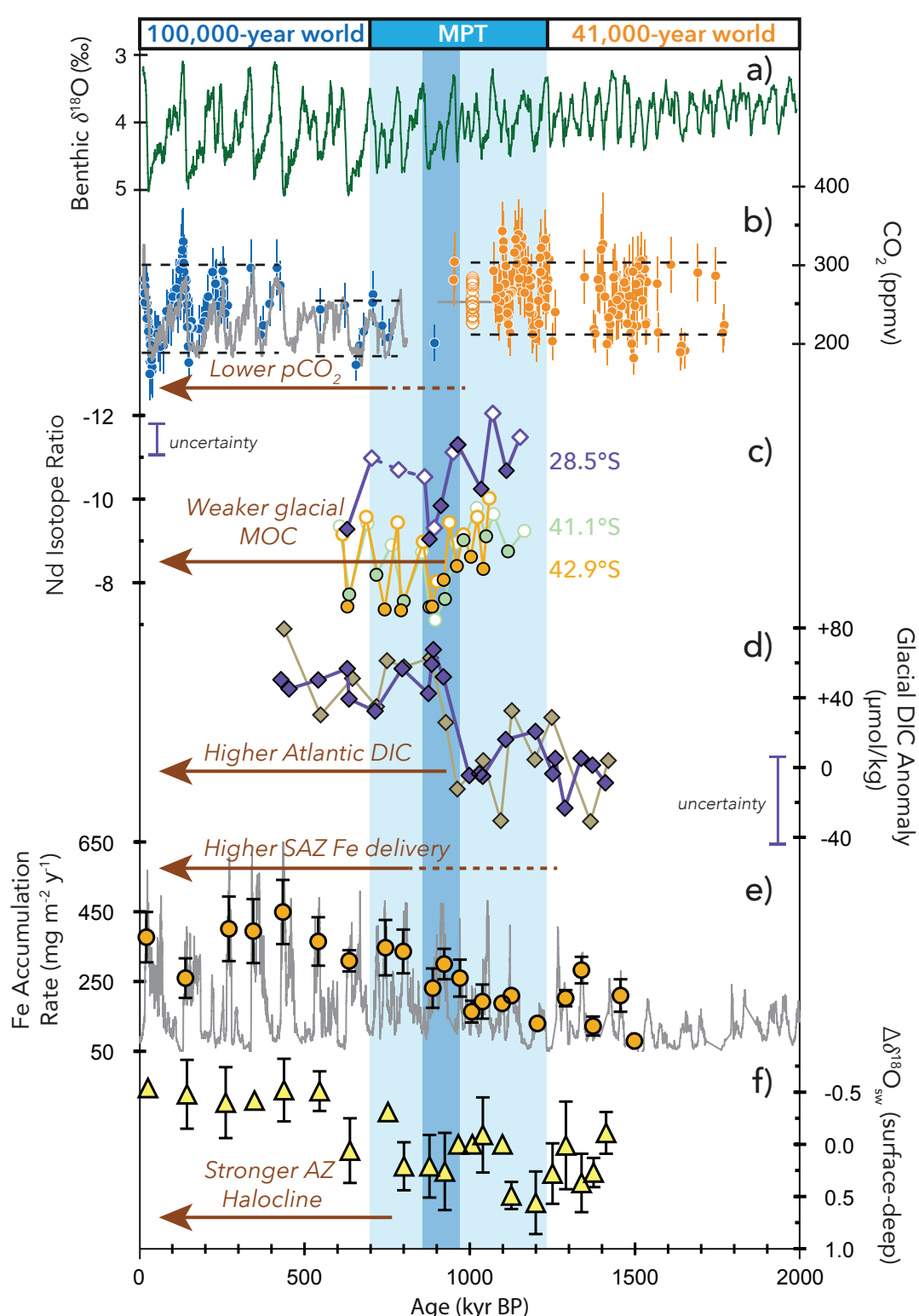

Figure 2: Paleoclimatology of the MPT. Brown arrows denote onset and duration of principal changes. Light blue vertical bar denotes MPT interval; dark blue bar denotes interval of the first 100-kyr glacial cycle within the MPT. (A) Benthic oxygen isotope stack (Lisiecki and Raymo 2005); (B) atmospheric $\mathrm{CO}_{2}$ compilation (grey line: Bereiter et al. 2015 compilation; open circles: Higgins et al. 2015; blue and orange filled circles: Dyez et al. 2018 compilation); (C) glacial (filled) and interglacial (open circles) deep Atlantic circulation from $\varepsilon_{\text {Nd }}$ (purple: Farmer et al. 2019; light orange/green: Pena and Goldstein 2014); (D) glacial deep Atlantic dissolved inorganic carbon content calculated from benthic foraminifer B/Ca (purple: Farmer et al. 2019; olive: Lear et al. 2016 and Sosdian et al. 2018); (E) Subantarctic Zone (SAZ) iron flux (line) and binned glacial maxima averages (circles) (Martínez-García et al. 2011); (F) density gradient between Antarctic Zone (AZ) surface and deep waters (Hasenfratz et al. 2019).

and nutrient-enriched after 950 kyr BP throughout the Atlantic Ocean. Translated to total dissolved carbon, these observations support a $\sim 50 \mu \mathrm{mol} / \mathrm{kg}$ increase during glacials after 950 kyr BP (Fig. 2d), equivalent to a 50 billion ton increase in carbon inventory throughout the deep Atlantic (Farmer et al. 2019). Pairing this information with $\varepsilon_{\mathrm{Nd}^{\prime}}$ Farmer et al. (2019) demonstrated that this deep-ocean carbon accumulation coincided with weakened deep Atlantic Ocean circulation (Fig. 2c-d), suggesting that weaker circulation facilitated accumulation of carbon and other nutrients in the deep Atlantic.

The implications of deep Atlantic carbon storage on $\mathrm{CO}_{2}$ are difficult to quantify because no simple equivalence exists between carbon concentration in the deep Atlantic Ocean and atmospheric $\mathrm{CO}_{2}$. In model simulations, the magnitude of $\mathrm{CO}_{2}$ reduction from weaker Atlantic circulation depends upon nutrient consumption in the surface Southern Ocean (Hain et al. 2010); with higher nutrient consumption, $\mathrm{CO}_{2}$ sequestration is strengthened. MartínezGarcia et al. (2011) reconstructed iron flux to the Subantarctic Southern Ocean, finding that peak glacial iron input increased around the beginning of the MPT (ca. $1250 \mathrm{kyr} \mathrm{BP),}$ with integrated glacial iron input increasing more gradually over the MPT (Fig. 2e). If this flux represents bioavailable iron, then increasing Subantarctic iron fertilization across the MPT would have increased ocean $\mathrm{CO}_{2}$ sequestration (Fig. 2e; Chalk et al. 2017; Martínez-García et al. 2011). Addressing the hypothesis of increased stratification, Hasenfratz et al. (2019) reconstructed the glacial density contrast between surface and deep waters in the Antarctic Zone of the Southern Ocean, finding an increased density gradient around $700 \mathrm{kyr}$ BP indicating a stronger halocline and longer surface-ocean residence time (Fig. 2f). This implies that a water-column density barrier to $\mathrm{CO}_{2}$ outgassing in the Southern Ocean strengthened by the end of the MPT.

In summary, three key oceanic pathways for atmospheric $\mathrm{CO}_{2}$ drawdown - deep Atlantic Ocean circulation, Subantarctic iron fertilization, and Southern Ocean stratification - all shifted towards favoring a stronger ocean $\mathrm{CO}_{2}$ sink and reduced atmospheric $\mathrm{CO}_{2}$ across the MPT. Yet all three pathways differ in their timing, and these scenarios are not necessarily exhaustive. For example, Kender et al. (2018) argue for enhanced stratification in the Bering Sea after 950 kyr BP (Fig. 1, white triangle), which may have also amplified oceanic $\mathrm{CO}_{2}$ drawdown.

Thus, evaluating the relative and cumulative $\mathrm{CO}_{2}$ impact of these pathways is an important focus for future MPT research. At the same time, sparse records of key ocean- $\mathrm{CO}_{2}$ pathways across the MPT must be expanded - particularly from the Pacific, which is the largest carbon reservoir in the modern ocean (Fig. 1). High-resolution atmospheric $\mathrm{CO}_{2}$ reconstructions are also needed to constrain the precise timing of MPT $\mathrm{CO}_{2}$ change, especially around $900 \mathrm{kyr} \mathrm{BP}$, and to evaluate the relative importance of different oceanic processes (Fig. 2b). By expanding these proxy applications and integrating available evidence, paleoclimatologists will progress towards a mechanistic understanding of the controls on this crucial window of Earth's climate evolution, encompassing the rise of hominids and the background climate that mankind is altering today.

\section{AFFILIATIONS}

'Department of Geosciences, Princeton University, NJ, USA

${ }^{2}$ Max-Planck Institute for Chemistry, Mainz, Germany ${ }^{3}$ Department of Earth and Environmental Sciences, Columbia University, New York, NY, USA ${ }^{4}$ Lamont-Doherty Earth Observatory of Columbia University, Palisades, NY, USA

${ }^{5}$ Department of Earth and Ocean Dynamics, University of Barcelona, Spain

\section{CONTACT}

Jesse R. Farmer: jesse.farmer@princeton.edu

\section{REFERENCES}

Bereiter B et al. (2015) Geophys Res Lett 42: 542-549 Chalk TB et al. (2017) Proc Natl Acad Sci 114: 13114-13119 Clark PU et al. (2006) Quat Sci Rev 25: 3150-3184

Dyez K et al. (2018) Paleoceanogr Paleocl 33: 1270-1291 Farmer JR et al. (2019) Nat Geosci 12: 355-360 Hasenfratz A et al. (2019) Science 363: 1080-1084 Hain MP et al. (2010) Glob Biogeochem Cy 24: GB40239 Higgins J et al. (2015) Proc Natl Acad Sci 112: 6887-6891 Kender et al. (2018) Nat Commun 9: 5386

Lauvset SK et al. (2016) Earth Syst Sci Data 8: 325-340 Lear CH et al. (2016) Geology 44: 1035-1038 Lisiecki L, Raymo M (2005) Paleoceanography 20: PA1009 Lynch-Stieglitz J, Marchitto TM (2014) Treatise on Geochemistry (2nd Edition): 438-451

Martínez-Garcia A et al. (2011) Nature 476: 312-315 Pena L, Goldstein SL (2014) Science 345: 318-322 Sosdian SM et al. (2018) Paleoceanogr Paleocl 33: 546-562 